\title{
Mapping diabetes burden by school-district for school-based diabetes prevention interventions in selected cities in Michigan, USA
}

\author{
Nurjannah Nurjannah, ${ }^{1}$ Amy B. Curtis, ${ }^{2}$ Kathleen M. Baker, ${ }^{3}$ Rajib Paul ${ }^{4}$ \\ ${ }^{1}$ Medical School, Public Health Department, Universitas Syiah Kuala, Banda Aceh, Indonesia; \\ ${ }^{2}$ Behavioral Health Administration, State Hawaii Department of Health, Honolulu, HI, USA; \\ ${ }^{3}$ Department of Geography, Western Michigan University, Kalamazoo, MI, USA; ${ }^{4}$ Department of Public \\ Health Sciences, University of North Carolina, Charlotte, NC, USA
}

\author{
Correspondence: Nurjannah Nurjannah, Medical School, Public Health \\ Department, Universitas Syiah Kuala, 23373, Indonesia. \\ Tel.: +62.6513611795. \\ E-mail: nurjannah_dr@unsyiah.ac.id
}

Key words: Diabetes; school districts; geographic information systems; years potential life lost; school-based diabetes prevention; USA.

Acknowledgements: the authors would like to thank Kalamazoo Health and Community Services (KHCS) Department and Centre for Health Data Research Analysis and Mapping (HDReAM) at the Western Michigan University for providing access to the records used in this study.

Funding: this work was supported by the Student Award Program grant from the Blue Cross and Blue Shield Michigan (BCBSM) Foundation in 2016. The findings in this article are those of the authors and do not necessarily represent the views of BCBSM.

Contributions: each author contributed substantially to the article; NN produced manuscript, conception of ideas, and data analysis; AC refined manuscript, conception of ideas and involved in study design; $\mathrm{KB}$ refined manuscript and involved in study design. RP refined manuscript.

Conflict of interests: the authors declare no potential conflict of interests.

Ethical clearance: the study was approved by the Western Michigan University (WMU) Human Subject Institutional Board.

Data availability: the diabetes prevalence datasets generated and/or analysed during the current study are available in the CDC website for 500 Cities project, https://www.cdc.gov/500cities/index.htm. The mortality dataset that support the findings of this study are available from the collaboration between KHCS Department and the Centre for Western Michigan University but restrictions apply to the availability of these data, which were used under license for the current study, and so are not publicly available.

Received for publication: 4 November 2020 .

Revision received: 27 March 2021.

Accepted for publication: 27 March 2021.

(C) Copyright: the Author(s), 2021

Licensee PAGEPress, Italy

Geospatial Health 2021; 16:941

doi:10.4081/gh.2021.941

This article is distributed under the terms of the Creative Commons Attribution Noncommercial License (CC BY-NC 4.0) which permits any noncommercial use, distribution, and reproduction in any medium, provided the original author(s) and source are credited.

\begin{abstract}
To decrease diabetes morbidity and mortality rates, early interventions are needed to change lifestyles that are often cemented early, making school-based interventions important. However, with limited resources and lack of within-county diabetes data, it is difficult to determine which local areas require intervention. To identify at-risk school districts, this study mapped diabetes prevalence and related deaths by school district using geographic information systems (GIS). The 2010-2014 records of diabetes-related deaths were identified for 13 cities in Michigan, USA. Diabetes prevalence was estimated using the weighted average of population by school district from the '500 Cities Project' of the Centres of Disease Control and prevention (CDC). Prevalence and mortality rates were mapped by school district and the correlation between diabetes prevalence and mortality rate analysed using the Spearman's rank correlation. Years of potential life lost (YPLL) were calculated using a 75-year endpoint. The result indicated there were geographic variations in diabetes prevalence, mortality and YPLL across Michigan. Most census tracts in the cities of Detroit, Flint and downtown Grand Rapids had higher diabetes prevalence and mortality rate with $r_{s}(628)=0.52, \mathrm{P}<0.005$. School districts with high mortality rates also had high prevalence with $r_{s}$ $(13)=0.72, \mathrm{P}=0.002$. Flint City School District showed a higher rate of diabetes prevalence, death and YPLL than others and should thus be considered a priority for diabetes prevention interventions. Using school districts as the geographic spatial unit of analysis, we identified local variation in diabetes burden for targeting school-based diabetes prevention interventions.
\end{abstract}

\section{Introduction}

Diabetes is one of the most common chronic diseases in the United States (U.S.). Its prevalence remains high and according to the Centres for Disease Control and Prevention (CDC) it was also the seventh leading cause of death nationwide in 2017 (CDC, 2020a). Type 2 diabetes accounts for approximately $90 \%$ to $95 \%$ of all diabetes cases in the U.S. (CDC, 2020a), and is a disease resulting from an interaction between biological (non-modifiable) as well as behavioural and environmental (modifiable) risk factors (Murea et al., 2012). In public health, the focus is often on modifiable risk factors, such as unhealthy diet, lack of exercise (Macera, 2003) as well as environmental factors, such as availability to open spaces, walkable destinations and sidewalks (Dendup et al., 2018). 
To reduce morbidity and mortality related to diabetes, changing lifestyle patterns often becomes necessary (Diabetes Prevention Program Research Group, 2002). Behavioural patterns, such as an unhealthy diet and/or lack of exercise, developed during early age help to determine not only current health but also the risk of morbidity and mortality related to chronic diseases, including the occurrence of diabetes, in adult life (Lawrence et al., 2009). Thus, interventions that improve the development of healthy lifestyle patterns in school children are important for their future health (Braveman et al., 2008).

According to the National Conference of State Legislatures (NCSL) resources are limited in preventing and managing diabetes (NCSL, 2016) and because of this, sub-county information regarding diabetes prevalence is not widely available (CDC, 2019), it is important to find ways to identify where the highest risk groups are at sub-county level to efficiently target interventions, particularly at the school district level. However, data related to diabetes are very limited at this level, e.g., diabetes risk factors among school children are collected through the Youth Risk Behaviour Surveillance System (YRBSS), but the data are only available at the state level (CDC, 2020b). Similarly, in Michigan, the equivalent of the YBRSS survey, called the Michigan Profile for Healthy Youth (MiPHY), is only publicly available at the county level (Michigan Department of Education, 2019). Another option to determine diabetes burden within school district boundaries is to examine diabetes risk factors among adults. CDC has conducted surveys using the Behavioural Risk Factor Surveillance System (BRFSS) that collects data regarding population health-related risk behaviours, chronic health conditions, and use of preventive services (CDC, 2020c). Again, these data are only available at the county level. Additionally, since diabetes prevalence data at the sub-county level are only available for selected big cities in the USA (CDC, 2019), a proxy must be used in all other cases. This study used vital records which include diabetes as an underlying and contributing causes of death as a proxy for examining diabetes burden as done by Barreto et al. (2007). Evaluation of addressmatched diabetes death records allows one to conduct evaluations in small geographic areas that can be used to target interventions.

In using local data on diabetes-related death, public health programs must also determine which geographic level would be most helpful for targeting interventions. School districts may be useful as they have previously been used by geographic analysis for targeting school-based diabetes prevention programs, such as Planet Health, the HEALTHY project, and the Kahnawake School Project, that involved school systems, teachers, students, parents, and communities in preventing diabetes risk behaviours
(Gortmaker et al., 1999; The HEALTHY Study Group, 2010; Nield et al., 2013). Schools have also been considered a good setting to implement health promotion strategies (Peterson \& Fox, 2007). Because schools can be considered as community hubs (Aboites et al., 2010), it is important that health promotion developed in schools represent the issues within school district boundaries. A school district is a common way of defining a community, because those in a school district share a similar immediate residential environment (Roux, 2001) and likely associate with one another due to shared common values about the education of children (Redding, 1991). Moreover, people may use school districts as a reference when deciding where to live based on the quality of schools (Holme, 2002).

This study used a geographic information system (GIS) to estimate diabetes burden at the school district level. Although it has been used in various diabetes studies using different geographic scales (Geraghty et al., 2010; Spratt et al., 2015), GIS analysis using school district boundaries has not been used to target diabetes prevention at schools to our knowledge. Given the high rate of diabetes prevalence and deaths related to diabetes as well as the importance of intervening early at schools, this study aimed to analyse whether diabetes-related deaths can be used as a proxy for the diabetes burden at the school district level to target for schoolbased diabetes prevention interventions.

\section{Materials and methods}

\section{Design}

This was a retrospective observational study using secondary data at individual, census tract and school district level. We selected 13 cities based on the data availability for diabetes prevalence estimation at census tract level from the 500 Cities Project: Dearborn, Detroit, Farmington Hills, Flint, Grand Rapids, Livonia, Rochester Hills, Southfield, Sterling Heights, Troy, Warren, Westland and Wyoming (CDC, 2016a).

\section{Data sources}

The study used several data sources including vital records, the 500 'Cities Project', and population data as described in Table 1.

Death records were obtained from the Michigan Department of Health and Human Services through a data sharing agreement between the Kalamazoo Health and Community Services (KHCS) Department and the Health Data Research, Analysis and Mapping

Table 1. Data, usage and sources.

\begin{tabular}{llll}
\hline No. & Data & Usage & Sources \\
1 & Vital records (diabetes-related deaths) & $\begin{array}{l}\text { To obtain the number of diabetes } \\
\text { deaths (underlying and associated } \\
\text { cause of death) at the individual level } \\
\text { To obtain the diabetes prevalence } \\
\text { at census tract level for selected } \\
\text { cities in Michigan }\end{array}$ & $\begin{array}{l}\text { The Michigan Department of Health and Human Services } \\
\text { through data sharing agreement between KHCS and } \\
\text { HDReAM WMU } \\
\text { CDC's '500 Cities Project' (publicly available) }\end{array}$ \\
\hline $3 \quad$ & $\begin{array}{l}\text { Population by school district, } \\
\text { census tract and blocks }\end{array}$ & $\begin{array}{l}\text { To calculate crude diabetes-related } \\
\text { mortality rate } \\
\text { School district and census tract boundaries }\end{array}$ & To obtain the map in shapefile \\
for GIS analysis & MGIS website
\end{tabular}


(HDReAM) Centre at Western Michigan University. We selected all death records of people residing in Michigan between 2010 and 2014 with diabetes as the cause of death, which includes diabetes as underlying or contributing cause; the former defined as diabetes directly leading to death (Part I of death certificate) and the latter when diabetes indirectly led to death (Part II of death certificate) (CDC, 2004). Both were combined into diabetes-related death.

For diabetes prevalence data, the study utilized the 2014 diabetes prevalence data at the census tract level from the 500 Cities Project. Crude diabetes prevalence was measured for respondents 18 years and older who were diagnosed by a health professional having diabetes other than gestational diabetes (CDC, 2016b). To be consistent with the crude diabetes prevalence rate obtained from the 500 Cities project, we calculated the crude rate for diabetesrelated death using population demographics from the 2010 U.S. Census obtained online through U.S. Census TIGER/Line ${ }^{\circledR}$ Shapefiles for school district, census tract, and block level (US Census Bureau, 2017). As the diabetes crude prevalence rate was estimated for population 18 years and older, we also calculated the crude death rate for the same age group.

School district and census tract map boundaries were retrieved from the Michigan Centre for Geographic Information website (State of Michigan, 2016). There were 638 census tracts in the 13 selected cities. We excluded eight of them due to populations less than 50 for privacy purposes, leaving the study with 630 census tracts for analysis. To be able to estimate diabetes prevalence rate at the school district level from the census tract estimates, we only included school districts that had $90 \%$ or more geographic overlap with the census tracts from the 500 Cities Project, to include as many as possible area within the school district boundaries. This resulted in 15 school districts for the analysis: Clarenceville, Detroit City, Farmington, Fitzgerald, Flint City, Godfrey-Lee, Godwin Heights, Grand Rapids, Livonia, Southfield, Troy, Van Dyke, Warren Consolidated, Warren Woods, and Wyoming.

\section{Address matching}

Death records were address matched in ArcMap 10.3 (ESRI, Redlands, CA, USA). To ensure confidentiality, we utilized an encrypted, password-protected server for all analyses as approved in the data sharing agreement between the KHCS Department and HDReAM at WMU. Of the total 43,012 diabetes-related deaths, 32,008 (74.48\%) records were matched. Common matching errors that required manually matching of the remaining addresses included misspellings of road names, abbreviated road names, and spacing between words or numbers. We reviewed all unmatched records and corrected where possible, leading to another 4221 matched addresses, making a total of 36,229 matched addresses (84.2\%). Approximately $15.8 \%$ of total diabetes-related deaths were not included in the analysis due to unmatched addresses in geocoding. A spatial join to census tracts identified 7718 death records within the census tracts included in the study. The number of matched addresses became 6558 records for school districts that had more than $90 \%$ geographic overlap with census tracts.

\section{Spatial and statistical analyses}

Because diabetes prevalence data were only available at the census tract level from the 500 Cities Project, we estimated the diabetes prevalence rate at the school district level using areal weighting interpolation assuming a uniform density of diabetes prevalence across a school district population. First, the census tracts from 500 Cities Project were intersected with the Michigan school district boundaries resulting in the fractional area of census tracts within school districts. Census blocks, for which general population estimates were available, were also intersected with the fractional area of census tracts within the school districts. Using areal interpolation, we estimated population for each fractional census tract using block populations. The fractional tract population was multiplied by the diabetes prevalence rate for the appropriate census tract and then summed up by school district.

To calculate crude diabetes-related mortality rate, we estimated the total population for $2010-2014$ by multiplying the 2010 census total population aged 18 years and older for each geographic area by five. The number of deaths related to diabetes for individuals aged 18 years and older from 2010-2014 for each geographic area was divided by the total population for the area as described above and multiplied by 10,000 . We also examined whether diabetes-related death rates can be used as a proxy to describe diabetes burden at the school district level by analysing the correlation between diabetes prevalence and diabetes mortality rate using the Spearman rank correlation coefficient as the data were not normally distributed using SPSS software. We set the confident interval at $95 \%$ for two-sided hypothesis testing.

To estimate the influence of diabetes diagnosis on age of death, we examined years of potential life lost (YPLL). These calculations relied on the sum of the differences between a predetermined standard age and the ages of death for those who died before that standard age (CDC, 2012). As recommended by the CDC, we used a standard age of 75 years old (Kochanek et al., 2016). In this study, we presented the average YPLL to provide information about how prematurely individuals died.

\section{Results}

\section{Diabetes mortality rate and prevalence rate}

Because of the limited nature of the 500 cities Project data, the analysis focused on 13 cities located in three areas in Michigan: the greater Detroit area (10 school districts), Flint area (1 school district) and downtown Grand Rapids area (4 school districts). Thematic maps show diabetes-related mortality rate against diabetes prevalence rate by census tract and school district level (Figures 1 and 2). The maps demonstrate variations in diabetes prevalence and deaths across the cities at both levels. At the census tract level, diabetes prevalence rates ranged from $2.3 \%$ to $27 \%$, with a median of $13.3 \%$. The diabetes-related mortality rate ranged from 0 to 45.6 deaths per 10,000 population, with a median of 9.9 deaths. Urbanized census tracts in the city of Detroit (Figure 1A) and Flint and downtown Grand Rapids (Figure 1B) had higher diabetes prevalence and diabetes-related mortality rate than in the rest of the study area. When we examined the correlation between diabetes prevalence and diabetes-related mortality rate at the census tract level, there was a significant correlation with $r_{s}(628)=0.52$, $\mathrm{P}<0.005$, indicating that at the census tract level, the higher diabetes prevalence rate, the higher diabetes-related death.

At the school district level, diabetes prevalence rate ranged from $8.2 \%$ in Troy School District to $17.8 \%$ in Detroit City School District. Similarly, diabetes-related mortality rate was also found to be the lowest in Troy School District (4.9 deaths per 10,000 population), while the highest was in Flint City School District (16.5 deaths per 10,000 population) (Figure 2). When examining dia- 
betes-related mortality rate against diabetes prevalence at the school district level, there was a significant correlation between diabetes death and prevalence rate with $r_{s}(13)=0.72, \mathrm{P}=0.002$ (Figure 3). It shows that at the school district level, the higher diabetes prevalence rate, the higher diabetes-related death.

\section{Years of potential life lost}

In setting priorities for targeting school-based diabetes prevention interventions, analysis of crude mortality rate and YPLL may be used to show the burden of diabetes not only from the number of death relative to the population but also the temporal changes in mortality. By ranking mortality rate and YPLL, we were able to determine which school district had the highest burden relative to other school districts. When examining the number of deaths against YPLL, Godwin Heights Public Schools was ranked first for having the highest YPLL compared to others at 16.47 years $(95 \%$ CI 6.11, 26.83), but only had 58 total deaths, the third smallest number of deaths among school districts (Table 2). In terms of the number of deaths, Detroit City School District had the highest total number of deaths (3220), but the average YPLL was the fourth highest at 14.57 years $(95 \%$ CI $14.13,15.01)$ and the mortality rate was the sixth highest. When assessing YPLL against the mortality rate, Flint City School District had the highest mortality rate and ranked third in YPLL with 14.97 years [95\% CI 14.44, 15.49] (Table 2). Based on these figures, Flint City School District appears to have the highest burden of diabetes relative to others considering the highest mortality rate and the second highest number of deaths, followed by Detroit City School District due to the largest and highest mortality rate, even though the mortality rate and YPLL relatively low.

\section{Discussion}

This study explored the potential of using school district as a sub-county area of analysis in regions of the U.S., where school districts are not synonymous with county jurisdictions, to inform targeted school-based diabetes prevention interventions. Because the study used publicly available diabetes prevalence data, the methods could be useful in urbanized regions with limited resources. By geographically examining select cities at the census tract and school district level, variations in diabetes-related mortality rate, diabetes prevalence and YPLL across the cities were identified. All census tracts and school districts included in the study were considered part of urbanized areas or urban clusters with populations higher than 2500 people (US Census Bureau, 2020). The result showed that school districts located in highly dense, urbanized areas population $(\geq 50,000$ people) such as Detroit, Flint, and Southfield School Districts had higher diabetes-related mortality rate and diabetes prevalence than those in urban clusters (population between 2500 to 50,000 people), such as Clarenceville,
A

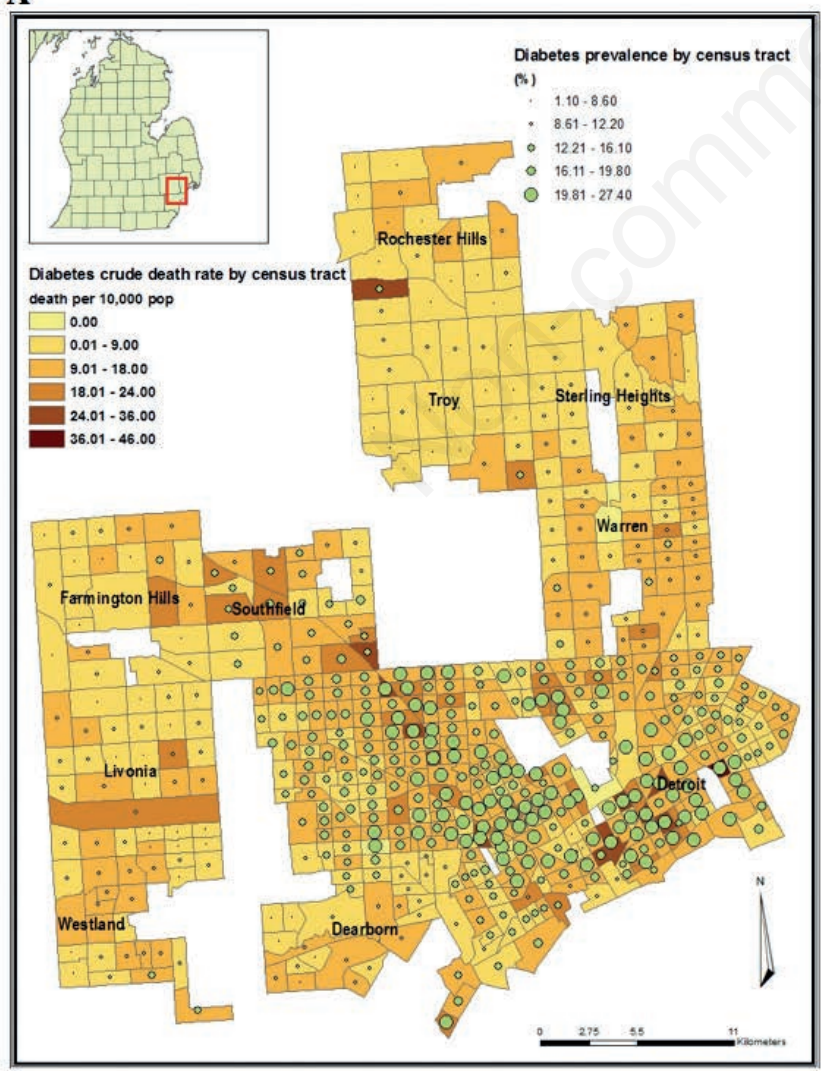

B

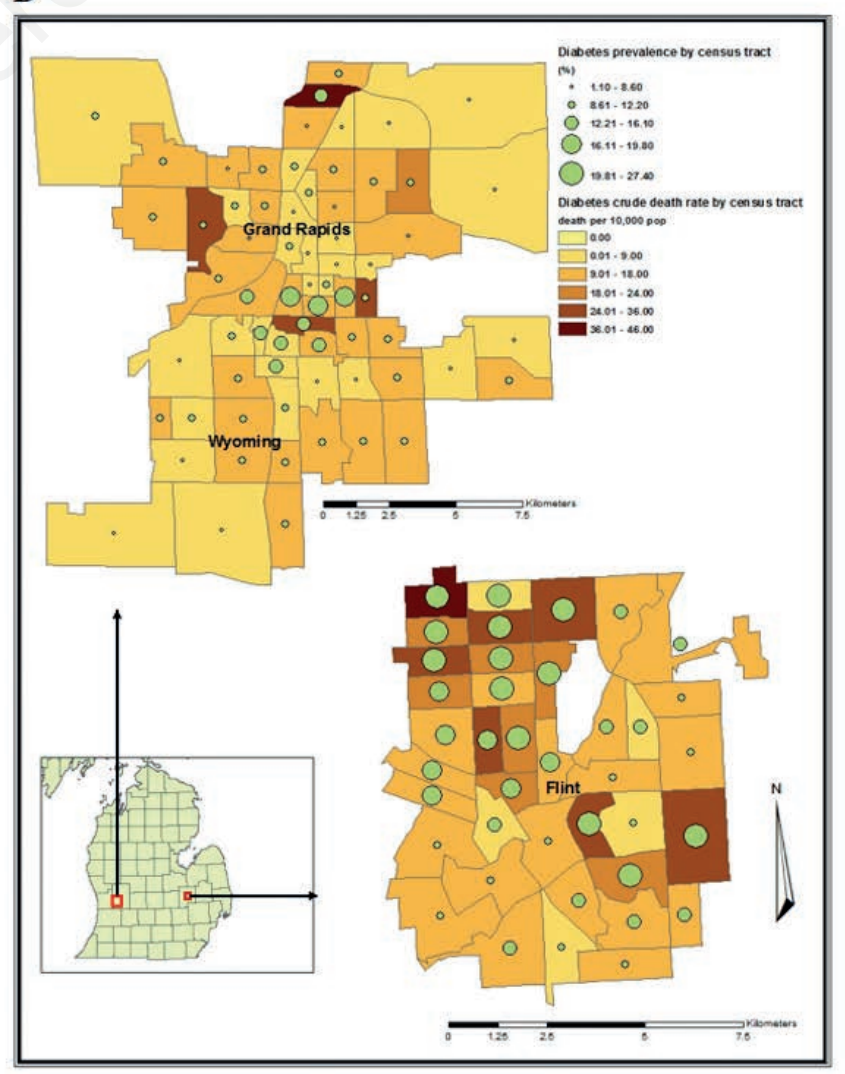

Figure 1. Diabetes-related mortality rate and diabetes prevalence by census tract for 13 cities in: A) Detroit area; and B) Grand Rapids and Flint areas, Michigan, 2010-2014. 


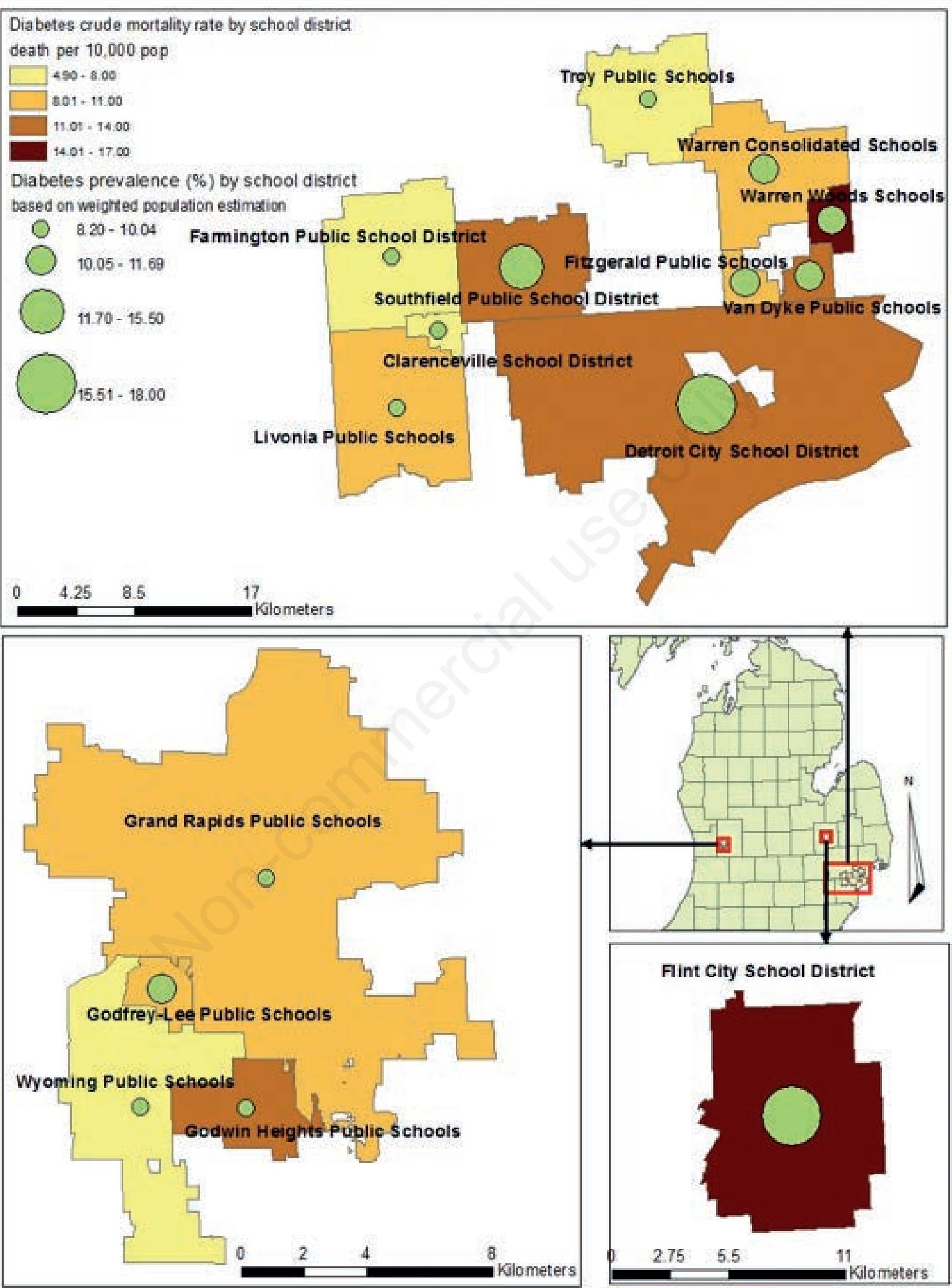

Figure 2. Diabetes mortality rate and diabetes prevalence by school district in Detroit area, Grand Rapids and Flint, Michigan, 2010-2014. 
Wyoming, and Godfrey-Lee School Districts. The result is consistent with previous study that found at sub-county level, urban areas with concentrated populations of low economic status had twice the rate of diabetes-related death and prevalence (Livingood et al., 2010).

In public health, mortality rate is frequently used to quantify human health status. However, the mortality rate does not completely address the issue of premature death (Gardner \& Sanborn, 1990). In the last two decades, attention has extended to include such measurement as YPLL for diabetes (Gregg et al., 2014). This study indicates geographic variations in premature death due to diabetes by school districts, information that can lead to improved health planning at the local level. A pattern of YPLL among varied populations can provide a description of the cause of premature death for population in a school district as one of informative measures for identifying targets for health planning. Together, mortality rate and YPLL provide a more comprehensive examination of diabetes deaths at sub-county level to support policy making and program planning. In this study, Flint City and Detroit City School Districts showed the higher burden of diabetes based on the analysis of mortality, prevalence rate, and YPLL than others. Thus, these school districts may be prioritized by local officials such as county health departments or school district offices for diabetes prevention interventions.

By understanding the burden of the disease at the school district level, preventive measures can be developed for addressing modifiable risk factors, reducing diabetes risks for population within the school district boundaries. Several school-based programs have been developed in preventing diabetes risk behaviours in Michigan such as Building Healthy Communities: Step Up for School Wellness programs initiated by Blue Cross Blue Shield of Michigan Foundation (BCBSM, 2016). The current study's findings might provide information to help such programs prioritize which school districts need targeted diabetes prevention interventions, especially when resources are limited (NCSL, 2016), and within-county data are lacking (CDC, 2019).
This study findings indicate that areas with high diabetes-related mortality rates also had high diabetes prevalence rates at both census tract and school district levels. Although the correlation at census tract and school district levels were statistically significant, the results were not consistent when examining the correlation at the census tract level by cities. The rate of diabetes-related death may not only depend on the number of people who have diabetes but also on other factors such as socioeconomic status, age, gender and race/ethnicity (Chaturvedi et al., 1998; Connolly et al., 2000; McBean et al., 2004; Link \& Mckinlay, 2009; Saydah \& Lochner, 2010; Spanakis \& Golden, 2013), as well as measurement error in

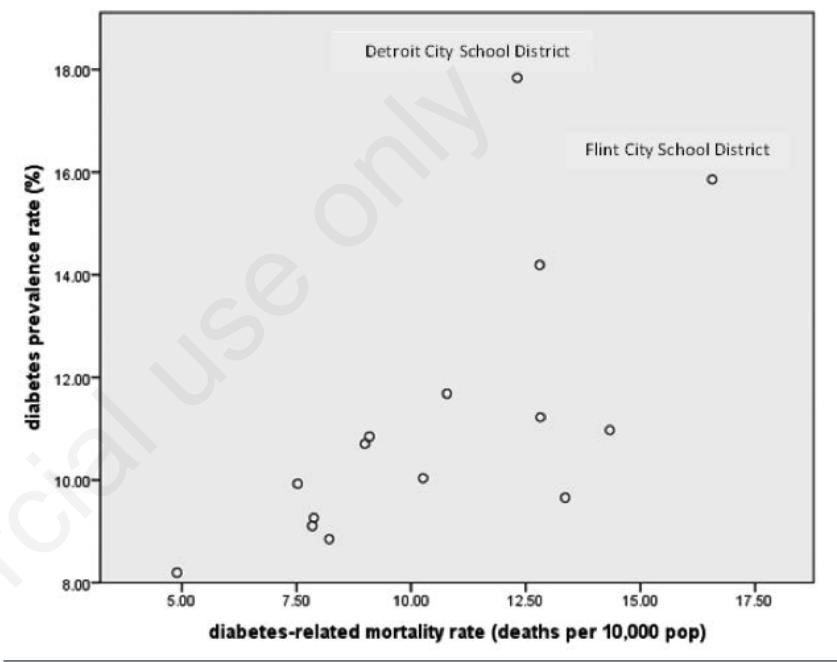

Figure 3. The scattergram of diabetes-related mortality rate and prevalence rate by school district in selected cities in Michigan, 2010-2014.

Table 2. Average number of years of potential life lost by school district in selected cities in Michigan, 2010-2014.

\begin{tabular}{|c|c|c|c|c|}
\hline No. & School District & $\begin{array}{l}\text { f diabetes-related death } \\
\qquad(95 \% \mathrm{CI})\end{array}$ & $\begin{array}{l}\text { Diabetes-related mortality rate } \\
\qquad(95 \% \mathrm{CI})\end{array}$ & $\begin{array}{c}\text { Number of diabetes-related } \\
\text { deaths }\end{array}$ \\
\hline 1 & Clarenceville School District & $10.67(2.17,19.16)$ & $7.53(3.47,11.83)$ & 35 \\
\hline 2 & Detroit City School District & $14.57(14.13,15.01)$ & $12.32(11.90,12.73)$ & 3224 \\
\hline 3 & Farmington Public School District & $11.75(10.01,13.48)$ & $7.88(6.64,9.12)$ & 259 \\
\hline 4 & Fitzgerald Public School District & $12.52(7.68,17.35)$ & $10.78(7.67,13.90)$ & 69 \\
\hline 5 & Flint City School District & $14.97(14.44,15.49)$ & $16.57(15.86,17.28)$ & 617 \\
\hline 6 & Godfrey-Lee Public Schools & $13.37(7.19,19.54)$ & $9.09(7.47,10.71)$ & 22 \\
\hline 7 & Godwin Heights Public Schools & $16.47(6.11,26.83)$ & $13.36(11.04,15.69)$ & 58 \\
\hline 8 & Grand Rapids Public Schools & $12.90(12.31,13.49)$ & $10.26(9.20,11.33)$ & 704 \\
\hline 9 & Livonia Public Schools & $11.11(9.75,12.48)$ & $8.22(7.40,9.03)$ & 373 \\
\hline 10 & Southfield Public School District & $11.97(10.89,13.06)$ & $12.81(10.79,14.82)$ & 351 \\
\hline 11 & Troy School District & $11.25(10.21,12.28)$ & $4.90(4.27,5.53)$ & 119 \\
\hline 12 & Van Dyke Public Schools & $15.96(13.67,18.24)$ & $12.82(9.35,16.29)$ & 96 \\
\hline 13 & Warren Consolidated Schools & $13.07(9.80,16.35)$ & $8.99(8.29,9.70)$ & 406 \\
\hline 14 & Warren Woods Public Schools & $10.82(7.62,14.02)$ & $14.33(12.07,16.60)$ & 122 \\
\hline 15 & Wyoming Public Schools & $13.95(11.54,16.37)$ & $7.85(6.58,9.11)$ & 103 \\
\hline
\end{tabular}

YPLL, years of potential life lost; CI, confidence interval. Data source: Death records from the Michigan Department of Health and Human Services (MDHHS). 
both coding death certificates and through estimating prevalence when using self-report data from phone surveys.

Considering diabetes prevalence data are not widely available at sub-county level, there is a potential to use the number of diabetes deaths to describe diabetes burden at the sub-county level, as death records are available for the entire state of Michigan and can be accessed at the individual level. Moreover, diabetes-related death consists not only of death directly due to diabetes, but also any death indirectly caused by diabetes. Additionally, if we only examine diabetes as a direct cause of death, data obtained from death certificates would underestimate the burden of diabetes in a community, especially as a contributing cause of death (Barreto et al., 2007). Several methodological limitations should be noted from this study. First, diabetes prevalence rates were estimated from the self-report in national telephone survey through BFRSS. Second, due to subjective judgement of certifying medical examiner, the potential errors in cause of death on death certificates cannot be ruled out. Third, the study did not take into account migration, assuming that people who died of diabetes lived their entire lives in the area listed as their place of death. Fourth, the use of crude prevalence and mortality rates may be confounded by differences in the population structure of the school districts being compared. Finally, a small number of cases were found in several census tracts which may due to the unmatched addresses can underestimate the mortality rate.

\section{Conclusions}

It can be concluded that using school districts as the geographic level of analysis, we identified local variation in the diabetes burden at the sub-county level that can be used for targeting school-based diabetes prevention interventions. There is potential in using diabetes death records as a proxy to describe diabetes burden when data on diabetes prevalence are not widely available.

\section{References}

Aboites H, Bigum C, Bouvier R, Clanfield D, Kuehn L, Hatcher R, Houhton E, LeClaire M, Rowan L, Spreen CA, Vally S, 2010. The school as community hub: Beyond education's iron cage. Our Schools/Our Selves. Canadian Centre for Policy Alternatives 19(4):100. Available from: https://www.policyalternatives.ca/sites/default/files/uploads/publications/ourselves/docs/OSOS_Summer10_Preview.pdf

Barreto SM, Passos VM, Almeida SK, Assis TD, 2007. The increase of diabetes mortality burden among Brazilian adults. Revista Panamer Salud Públ 22:239-45.

Blue Cross Blue Shield of Michigan (BCBSM) Foundation, 2016. Nearly 150 schools statewide to join innovative health and wellness-based building healthy communities program. Available from: http://www.mibluesperspectives. com/news/nearly-150-schools-statewide-to-join-innovativehealth-and-wellness-based-building-healthy-communitiesprogram/ Accessed: 4 September 2020.

Braveman P, Sadegh-Nobari T, Egerter S, 2008. Early childhood experiences: Laying the foundation for health across a lifetime. Available from: https://folio.iupui.edu/bitstream/handle/ 10244/613/commissionearlychildhood062008.pdf Accessed: 3
January 2018.

CDC, 2004. Instructions for completing the cause-of-death section of the death certificate. Available from: http://www.cdc.gov/ nchs/data/dvs/blue_form.pdf Accessed: 6 September 2017.

CDC, 2012. Principles of epidemiology. An introduction to applied epidemiology and biostatistics. Available from: https://www.cdc.gov/csels/dsepd/ss 1978/SS1978.pdf Accessed: 6 September 2017.

CDC, 2016a. 500 Largest cities, ${ }^{*}$ by state and population. Available from: https://www.cdc.gov/places/about/500-cities2016-2019/pdfs/500-cities-by-state.pdf Accessed: 6 September 2017.

CDC, 2016b. 500 Cities: local data for better health. Health outcomes. Available from: https://www.cdc.gov/500cities/definitions/health-outcomes.htm Accessed: 6 September 2017.

CDC, 2019. 500 Cities Project: local data for better health. Available from: https://www.cdc.gov/500cities/ Accessed: 4 September 2020.

CDC, 2020a. National Diabetes Statistics Report, 2020. Atlanta, GA. U.S. Dept of Health and Human Services. Available from: https://www.cdc.gov/diabetes/pdfs/data/statistics/national-diabetes-statistics-report.pdf Accessed: 4 September 2020.

CDC, 2020b. YRBSS. Available from: https://www.cdc.gov/ healthyyouth/data/yrbs/index.htm_Accessed: 4 September 2020

CDC, 2020c. Behavioral risk factor surveillance system (BRFSS). Available from: https://www.cdc.gov/brfss/index.html Accessed: 4 September 2020

Chaturvedi N, Jarrett J, Shipley MJ, Fuller JH, 1998. Socioeconomic gradient in morbidity and mortality in people with diabetes: cohort study findings from the Whitehall study and the WHO Multinational Study of Vascular Disease in Diabetes. BMJ 316:100-5.

Connolly V, Unwin N, Sherriff P, Bilous R, Kelly W, 2000. Diabetes prevalence and socioeconomic status: a population based study showing increased prevalence of type 2 diabetes mellitus in deprived areas. J Epidemiol Community Heal 54:173-7.

Dendup T, Feng X, Clingan S, Astell-Burt T, 2018. Environmental risk factors for developing type 2 diabetes mellitus: a systematic review. Int J Environ Res Public Health 15:78.

Diabetes Prevention Program Research Group, 2002. Reduction in the incidence of type 2 diabetes with lifestyle intervention or metformin. N Engl J Med 346:393-403.

Gardner JW, Sanborn JS, 1990. Years of potential life lost (YPLL) - What does it measure?. Epidemiology 1:322-9.

Geraghty EM, Balsbaugh T, Nuovo J, Tandon S, 2010. Using geographic information systems (GIS) to assess outcome disparities in patients with type 2 diabetes and hyperlipidemia. J Am Board Fam Med 23:88-96.

Gortmaker SL, Peterson K, Wiecha J, Sobol AM, Dixit S, Fox MK, Laird N, 1999. Reducing obesity via a school-based interdisciplinary intervention among youth. Planet Health Arch Pediatr Adolesc Med 153:409.

Gregg EW, Zhuo X, Cheng YJ, Albright AL, Narayan KV, Thompson TJ, 2014. Trends in lifetime risk and years of life lost due to diabetes in the USA, 1985-2011: a modelling study. Lancet Diabetes Endocrinol 2:867-74.

Holme JJ, 2002. Buying homes, buying schools: school choice and the social construction of school quality. Harvard Educ Rev 72:177-206. 
health-coverage-state-laws-and-programs.aspx Accessed: 4 September 2020.

Nield A, Quarrell S, Myers S, 2013. Community based early intervention for the prevention of type 2 diabetes: a case report of the Kahnawake schools diabetes prevention project. J Diabetes Metab 4:1-6.

Peterson KE, Fox MK, 2007. Addressing the epidemic of childhood obesity through school-based interventions: What has been done and where do we go from here? J Law Med Ethics 35:113-30.

Redding S, 1991. What is a school community, anyway. School Commun J 1:7-9.

Roux AVD, 2001. Investigating neighborhood and area effects on health. Am J Public Health 91:1783-9.

Saydah S, Lochner K, 2010. Socioeconomic status and risk of diabetes-related mortality in the US. Public Health Rep 125:377-88.

Spanakis EK, Golden SH, 2013. Race/ethnic difference in diabetes and diabetic complications. Curr Diab Rep 13:814-23.

Spratt SE, Batch BC, Davis LP, Dunham AA, Easterling M, Feinglos MN, Granger BB, Harris G, Lyn MJ, Maxson PJ, Shah BR, 2015. Methods and initial findings from the Durham Diabetes Coalition: Integrating geospatial health technology and community interventions to reduce death and disability. J Clin Transl Endocrinol 31:26-36.

State of Michigan, 2016. GIS open data. Available from: http://gis.michigan.opendata.arcgis.com/datasets/f40e3bf5815 e4045a68c53af572690f6_10 Accessed: 6 September 2017.

The HEALTHY Study Group, 2010. A school-based intervention for diabetes risk reduction. N Engl J Med 363:443-53.

US Census Bureau, 2017. TIGER/Line ${ }^{\circledR}$ Shapefiles and TIGER/Line ${ }^{\circledR}$ Files. Available from: https://www.census. gov/geo/maps-data/data/tiger-line.html Accessed: 6 September 2017.

US Census Bureau, 2020. 2010 Census Urban Area FAQs. Available from: https:/www.census.gov/programs-surveys/ geography/about/faq/2010-urban-area-faq.html 